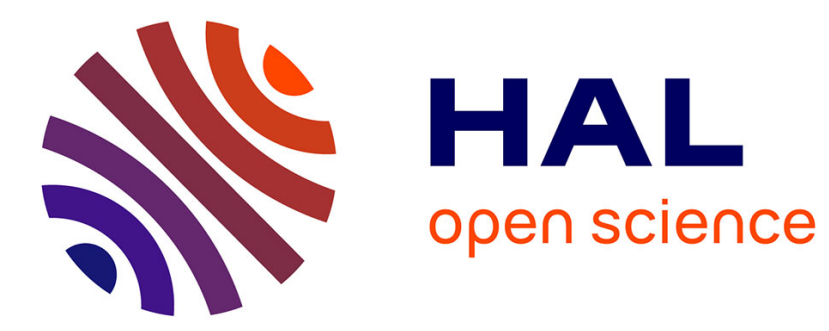

\title{
Performance of the reflected beam sputter source
}

K. Brand

\section{To cite this version:}

K. Brand. Performance of the reflected beam sputter source. Revue de Physique Appliquée, 1977, 12 (10), pp.1453-1457. 10.1051/rphysap:0197700120100145300 . jpa-00244346

\section{HAL Id: jpa-00244346 https://hal.science/jpa-00244346}

Submitted on 1 Jan 1977

HAL is a multi-disciplinary open access archive for the deposit and dissemination of scientific research documents, whether they are published or not. The documents may come from teaching and research institutions in France or abroad, or from public or private research centers.
L'archive ouverte pluridisciplinaire HAL, est destinée au dépôt et à la diffusion de documents scientifiques de niveau recherche, publiés ou non, émanant des établissements d'enseignement et de recherche français ou étrangers, des laboratoires publics ou privés. 


\title{
PERFORMANCE OF THE REFLECTED BEAM SPUTTER SOURCE
}

\author{
K. BRAND \\ Ruhr-Universität Bochum, Dynamitron-Tandem-Laboratorium, Universitätsstraße 150, \\ 4630 Bochum 1, Germany
}

\begin{abstract}
Résumé. - La source d'ions sputter à faisceau réflecté est une modification de la source Hiconex 834. Au lieu d'utiliser un cône, la cible a la forme d'un cylindre composé du matériau que l'on veut accélérer. Elle est bombardée par le faisceau réflecté de césium.

On présente quelques caractéristiques sur les performances de la source ainsi que les résultats des mesures sur la transmission et l'émittance. On a établi que la source modifiée est plus performante que l'originale pour la plupart des caractéristiques.
\end{abstract}

\begin{abstract}
The reflected beam sputter source is a modification of a Hiconex 834 sputter source. Instead of target cones small cylindrical pills of target material are being used which are bombarded by the reflected cesium beam. Some output data, results on transmission and emittance measurements are presented. The source turns out to be superior to the original in most properties.
\end{abstract}

1. Introduction. - The experimental program at Bochum requiring high intensity carbon and silicon beams led to the purchase and installation of a Hiconex 834 sputter source [1] on the ORTEC injector of the Bochum Tandem Dynamitron (Fig. 1). The source

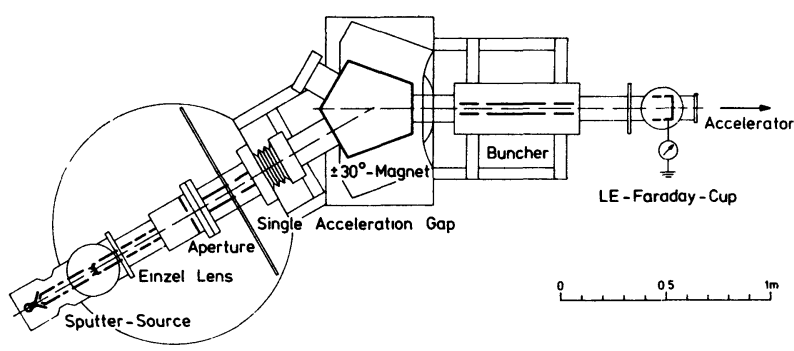

FIG. 1. - Bochum Tandem Injector.

is being used in exchange with a direct extraction type duoplasmatron on the positive input leg of the $\pm 30^{\circ}$ inflection magnet. The negative heavy ion beam is focused by a retarding field einzel lens through the sweep aperture of the injector pulsing system. This aperture had to be opened up from 2.8 to $6 \mathrm{~mm}$ mainly because of alignment problems. The beam is accelerated to about $100 \mathrm{keV}$ by a single gap acceleration lens and analysed in the $30^{\circ}$ inflection magnet. The image is formed at the center of the buncher tube. Instead of the buncher tube apertures of 5 and $2.5 \mathrm{~mm}$ diameter can be placed at this point in order to improve the resolution or to reduce the beam intensity injected into the accelerator. The beam intensity is measured further down with the LE retractable fara- day cup. The accelerator (Fig. 2) is a $4 \mathrm{MV}$ Tandem Dynamitron equipped with a gas stripper. Two titanium sublimation pumps are installed at both ends of the stripper canal.

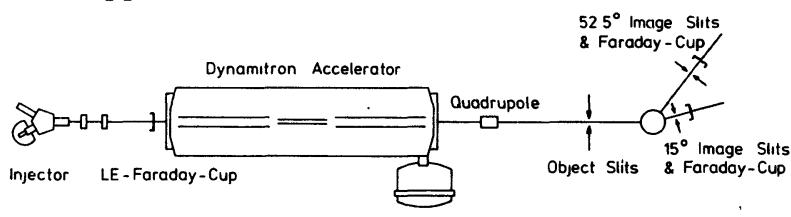

Fig. 2. - Bochum Tandem Dynamitron.

The analysing magnet at the high energy side has its main output leg at an angle of $+52.5^{\circ}$ serving a switching magnet and a heavy ion leg at $+15^{\circ}$. This leg has to be used for ion beams with a mass energy product higher than 56. Both legs are equipped with regulating slits and a retractable faraday cup. All measurements reported here have been made in one of these cups.

2. Description of the source. - The General Ionex 834 sputter source has been described in detail in ref. [2]. A schematic view is shown in figure 3. The source is a modified Middleton [3] source. The modification consists of an additional einzel lens for the cesium beam [4]. The unique design of this einzel lens - the medium electrode is split up into four segments - allows the cesium beam to be focused down to a small spot and to be steered onto the edge of the target cone aperture. This defines the area of origin of the ions which results in an improvement of the emittance of the negative beam. 


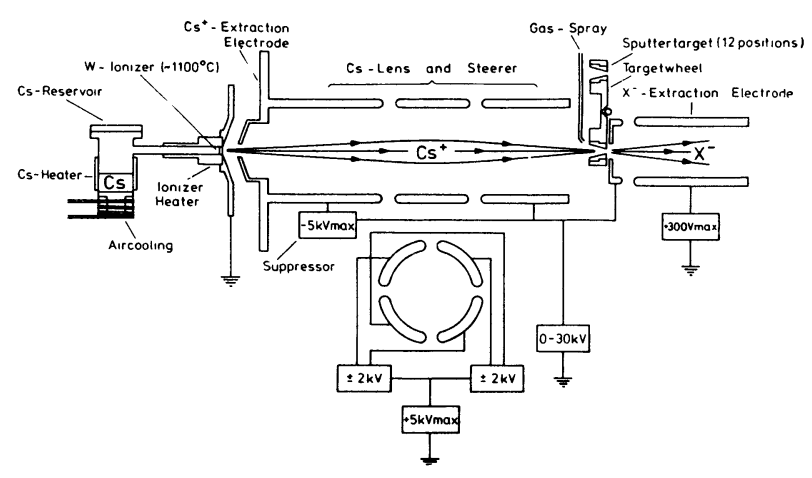

FIG. 3. - Schematic view of the Hiconex 834 sputter source.

This source had a very good start, the only difficulty made the transport mechanism of the target wheel. At the beginning the source has been used primarily for the production of ${ }^{12} \mathrm{C}^{2+}$ beams at $7 \mathrm{MeV}$ in an astrophysics experiment requiring some $30 \mu \mathrm{A}$ on target. One of the best runs with respect to output and transmission was accomplished using a cone with a $3 \mathrm{~mm}$ end hole. This result was in contradiction to most of our test measurements which indicated a slightly higher transmission for beams from $2 \mathrm{~mm}$ cones. The reason was found on the back of the cone (Fig. 4). The transport mechanism had set the cone about $3 \mathrm{~mm}$ outside the axis of the source. The cesium beam had

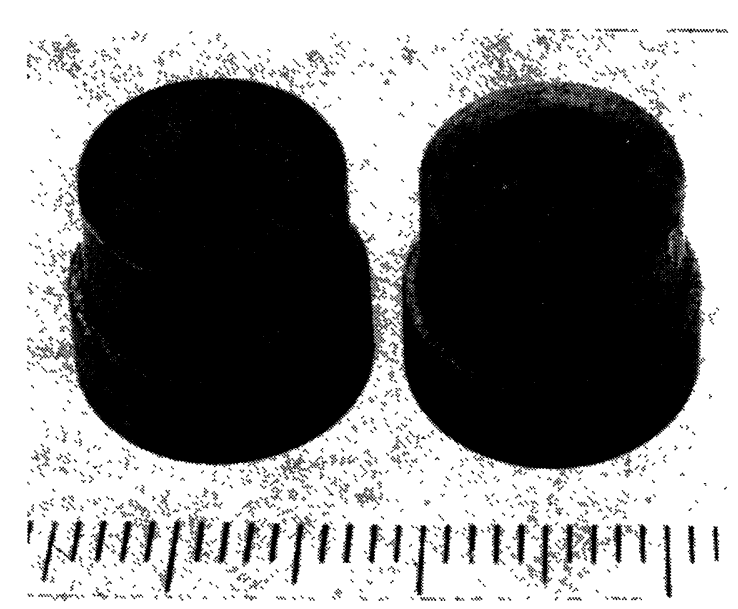

FIG. 4. - Back of off-set cones.

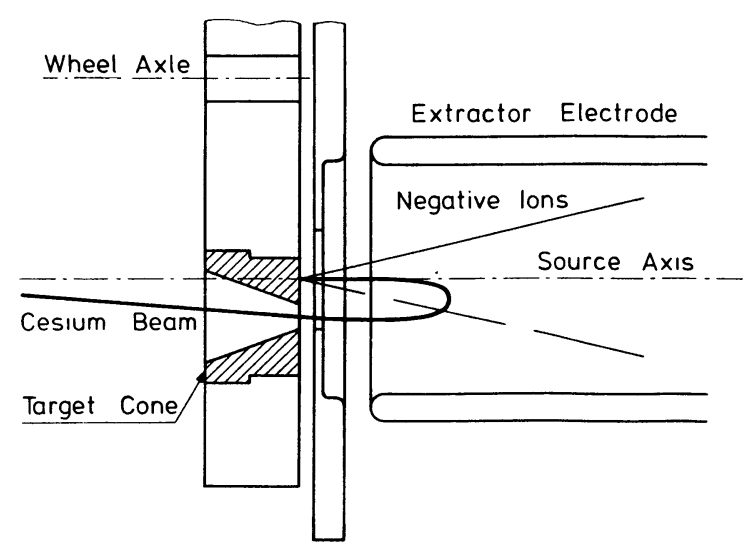

FIG. 5. - Beam production with off-set target cone. been steered through the cone hole into the extraction field of the negative ions (Fig. 5). This field has the geometry of an electrostatic mirror with focussing properties. By the combined action of the mirror and the einzel lens the cesium beam was focussed to a small spot around the axis of the extraction field.

Under these conditions the cesium ions are bombarding the flat back of the cone, the angle of incidence is almost $90^{\circ}$ to the surface. In this case the angular distribution of the sputtered particles is highly symmetrical around the surface normal [5]. Since the origin of the sputtered particles is on the axis of the extraction field, this axis and the axis of symmetry of the angular distribution of the sputtered particles coincide. When the cesium beam bombards the inner surface of a cone in the centered position, the angle of incidence is close to $70^{\circ}$ to the surface normal. In this case the angular distribution is asymmetric and the direction of preferred emission is different from the direction of negative ion extraction. Therefore one could expect the emittance of the beam produced by the reflected cesium beam to be lower than that produced on the inner cone surface [6]. This argumentation led to the design of the reflected beam sputter source. The principal and some output and transmission measurements for carbon beams in comparison with cone data have been reported recently [7]. The cone is replaced by a molybdenum insert with a hole for the cesium beam and a bore on the back to accept cylindrical pills of target material (Fig. 6). Twelve inserts are arranged on the target wheel in such a way that the hole is offset by $3 \mathrm{~mm}$ with respect to the source axis. The pill diameter is $5 \mathrm{~mm}$, its thickness $2 \mathrm{~mm}$. These dimensions have been chosen because of the existing pressing tool of the laboratory press. Smaller sizes down to $3 \mathrm{~mm}$ diameter are possible. The pills are held in place by a $1 \mathrm{~mm}$ molybdenum shield.

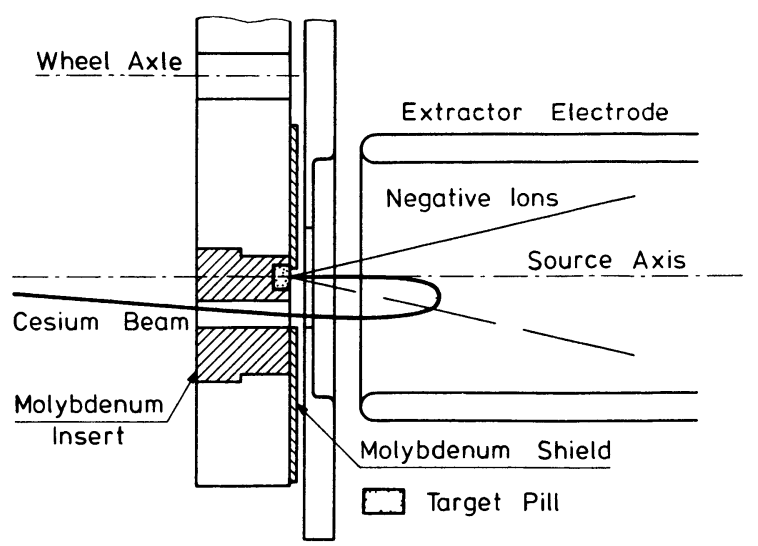

Fig. 6. - Scheme of the reflected beam sputter source.

The dimensions of the pills are not critical, but it is important that they are fixed in the bore. Thin ones can be fixed underlaying aluminium or carbon foils. The latter has been used successfully for the determination of the end of the pills lifetime by periodic 
checks of the carbon output. A steep increase indicated the pill being punctured.

3. Output and transmission. - Some output data are compiled in table I. The extraction energy was 20-

TABLE I : Output of the reflected beam sputter source.

Reservoir

Temperature LE-Beam

\begin{tabular}{|c|c|c|c|}
\hline Ion & Material & ${ }^{\circ} \mathrm{C}$ & $\mu \mathrm{A}$ \\
\hline- & - & 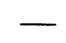 & - \\
\hline${ }^{1} \mathrm{H}^{-}$ & pressed Ti-sponge & & \\
\hline & loaded with $\mathrm{H}_{2}$ & 177 & 14.0 \\
\hline$B^{-}$ & pressed B, enriched & 160 & 1.45 \\
\hline${ }^{2} C^{-}$ & graphite & 228 & 120.0 \\
\hline $\mathrm{O}^{-}$ & $\mathrm{Ti}+\mathrm{O}_{2} \dot{\mathrm{G}} \mathrm{as}$ & 275 & 40.0 \\
\hline $19 \mathrm{~F}^{-}$ & pressed LiF & 190 & 8.0 \\
\hline $\mathrm{Si}$ & Si-single crystal & 237 & 36.0 \\
\hline $5^{-}$ & pressed $\mathrm{PbS}$ & 236 & 40.0 \\
\hline $\mathrm{Cl}$ & pressed $\mathrm{NaCl}$ & 166 & 16.8 \\
\hline $\mathrm{Cu}$ & pressed $\mathrm{Cu}$-shot & 210 & 2.8 \\
\hline $\mathrm{Br}$ & pressed $\mathrm{NaBr}$ & 150 & 33.0 \\
\hline As & pressed Ag-shot & 216 & 4.3 \\
\hline J & pressed $\mathrm{NaJ}$ & 170 & 26.5 \\
\hline $\mathrm{Al}$ & pressed Au-shot & 275 & 25.0 \\
\hline
\end{tabular}

$25 \mathrm{keV}$, the beam energy $90 \mathrm{keV}$. After rounding off some sharp edges in the source we are able now to run the extraction energy at $30 \mathrm{keV}$ which improves the output by a good percentage for some ions like gold and sulfur. Table II shows some transmission data. Estimating the total transmission using semi-empirical formulae [8] and measured charge state distributions [9] results in about $65 \%$ for carbon, $35 \%$ for silicon and $20 \%$ for iodine and gold. The terminal pumps have been used only in the case of the carbon beam. A more systematic measurement of heavy ion transmission had to be postponed since the accelerator

TABLE II : Transmission through the tandem Dynamitron.

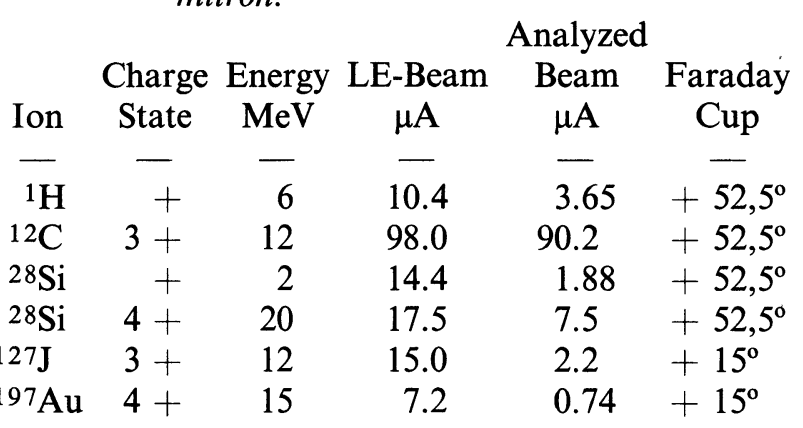

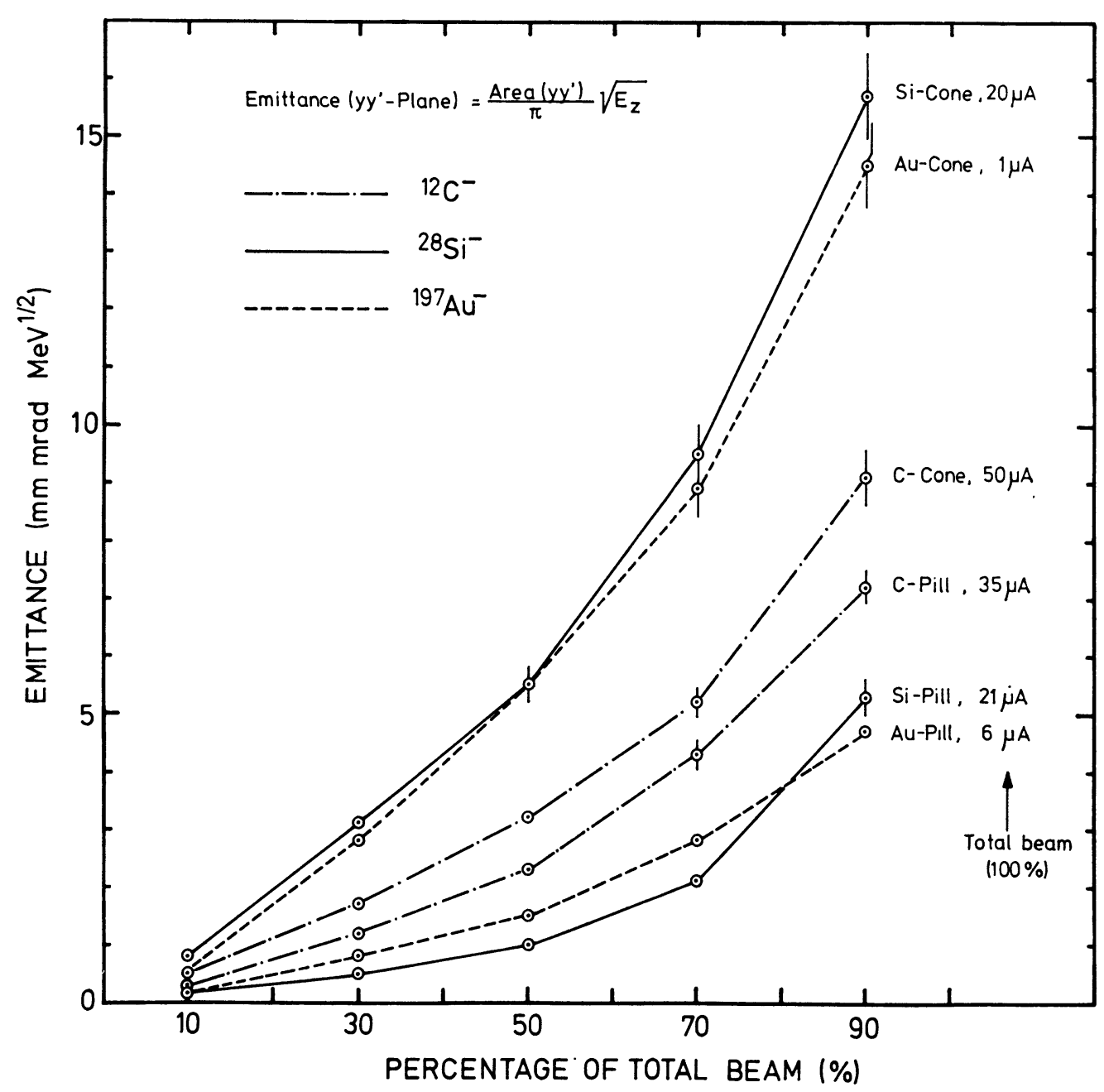

FIG. 7. - Emittance data of original and modified source. 
had to be shut down two months ago because of the failure of the plexiglas structure.

4. Emittance measurements. - Since the laboratory at Bochum does not own an emittance measurement device, I was very glad that Dr. Kutschera from the Physik-Department der Technischen Universität München made it possible to use the test injector of the Munich MP tandem [2]. The vertical emittance of carbon, silicon and gold beams has been measured.

The results are compiled in figure 7 together with cone data from ref. [2]. For carbon beams of similar intensity the emittance of the beam from the pill is smaller by about $20 \%$. This corresponds to the transmission measurements reported in ref. [7]. For silicon and gold the emittance is smaller by a factor of 3 . Whereas the silicon beams are of equal total intensity, the gold beam intensity from the pill is 6 times higher. The big difference between the emittance values of the gold beams from cone and pill and the small difference in the case of carbon may support the former argument that the relation between the direction of preferred emission of the sputtered particles and the direction of negative ion extraction is of major influence to the emittance of the negative beam together with a measurement reported by Betz [10]. He bombarded 12 different target materials including carbon and gold at $60^{\circ}$ to the surface normal, which is close to the angle of incidence of the cesium beam in the cone geometry of the original source. He found that the direction of preferred emission is $35-40^{\circ}$ to the normal for carbon and only $1-3^{\circ}$ for gold which means angles of $70-75^{\circ}$ to the direction of negative ion extraction for carbon, but angles as high as $107-109^{\circ}$ for gold.

Emittance patterns do not show the ring structure [11], which is characteristic for the Middleton source and which is reduced but still present in case of the refocussed Hiconex.

5. Ion efficiency. - Since all sputtered particles leave the surface of the pill into the direction of negative ion extraction, the ion efficiency which is defined here as the ratio between the mass carried by the beam to the LE cup and the mass lost from the pill is higher than in the case of the cone. This is demonstrated in figure 8 showing a silicon pill and a silicon cone which both produced $25 \mu \mathrm{A}$ in the LE cup for about 24 hours. The silicon pill lost $7.5 \mathrm{mg}$ which means an ion efficiency of about $8 \%$. A similar number has been found for a carbon pill, which delivered $12 \mu \mathrm{A}$ of ${ }^{12} \mathrm{C}$ for 50 hours and $22 \mu \mathrm{A}$ for 15 more hours with a loss of $5 \mathrm{mg}$. It can be seen on the picture that the main diameter of the cesium beam is about $1 \mathrm{~mm}$ having two tails. It is not clear yet where the distortions are generated. They can be due to the distorted field of the split einzel lens or more probably due to aberrations in the mirror. A computer study could answer the question and lead to a better geometry.

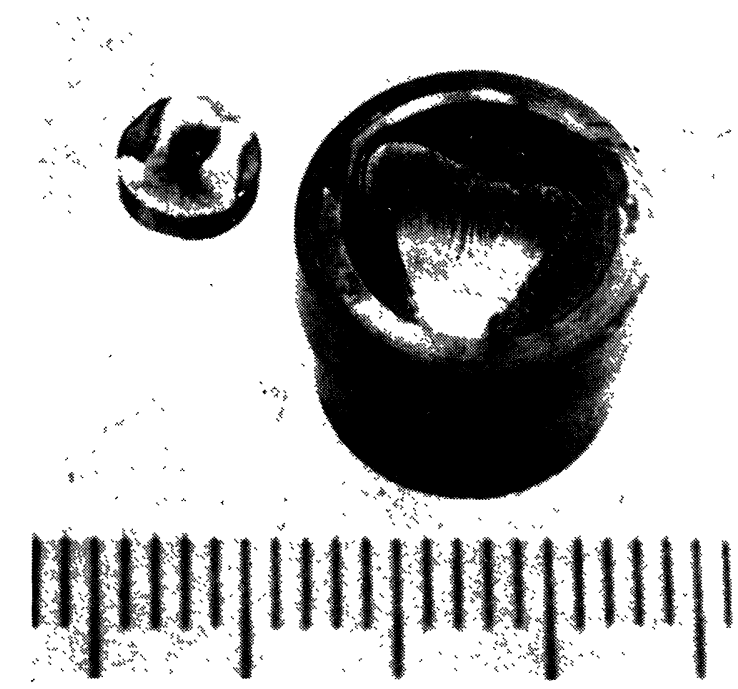

FIg. 8. - Used silicon cone and pill.

6. Effect of reflector bias voltage. - Both Hyder [4] and Ihmels [11] applied a small adjustable positive bias voltage to the negative ion extraction electrode which is at ground potential in the original source in order to reflect cesium ions escaping through the cone hole. Hyder reported that the application of a few hundred volts doubled the output in some cases. In the case of the reflected beam sputter source a bias voltage is expected to be very effective since the total beam is going through the insert and all cesium ions have to be decelerated to zero velocity before being reflected.

Figure 9 shows the effect of the reflector bias voltage for three different ion species. The lower curve of

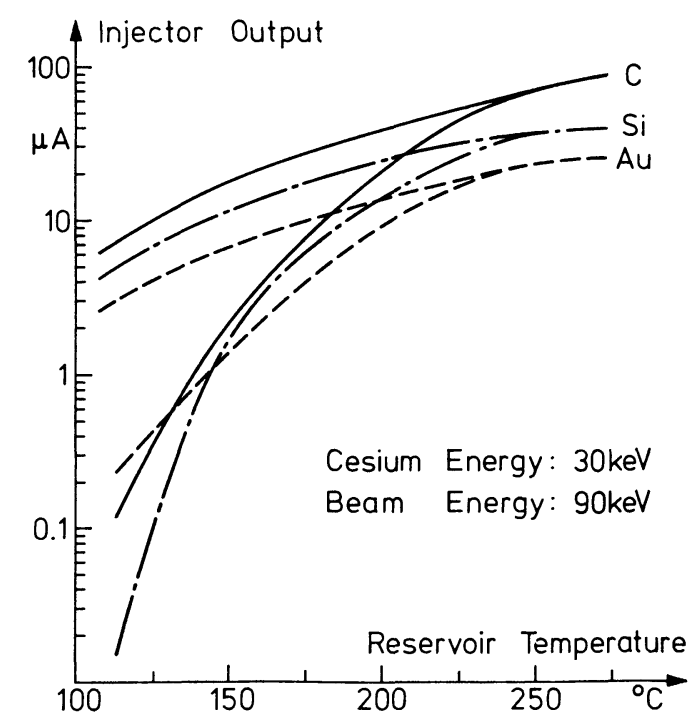

FIG. 9. - The effect of reflector bias voltage.

each pair shows the output without bias. It can be seen that the increase of the output is ranging from orders of magnitude for low reservoir temperatures, i.e. low cesium beams to zero for intense cesium beams. The amount of bias voltage required is starting 
above 200 volts and is coming down to zero with increasing cesium intensity, probably due to space charge build-up. Since for most experiments the maximum output is not required the source can be run at very low reservoir temperatures. In the case of silicon the source was unstable without the bias at low cesium intensity.

7. Conclusion. - The reflected beam sputter source is in regular use at Bochum since about 7 months. During this period the source has been operational for more than 1500 hours. No maintenance has been required except adding cesium and replacing pills. It exceeds the original Hiconex 834 source in output and emittance. Target pills are easily produced using a laboratory press, they require very little material. Ionizer lifetime is expected to be longer than in the original source, since backstreaming negative ions can be produced only on the molybdenum inserts.

I like to express my thanks to Dr. Kutschera, Mr. J. Huber and Mr. G. Korschinek of the PhysikDepartment der Technischen Universität München for the emittance measurements. The parts required to modify the source have been built in the shop of the Institut für Experimentalphysik I, Ruhr-Universität Bochum, their help and that of Mrs. D. Runzer and Mrs. D. Hake of the same institute who prepared the pictures was gratefully accepted.

\section{References}

[1] Manufactured by the General Ionex Corporation, Ipswich, Mass. U.S.A.

[2] Braun-Elwert G., Huber J., Korschinek G. and KutSCHERA W., Int. Conf. on the Physics of the Tandem. Trieste, Italy, 1976, to be published in Nucl. Instrum Methods.

[3] Middleton R. and Adams C. T., Nucl. Instrum. Methods 118 (1974) 229.

[4] Doucas G., MCK. Hyder H. R. and Knox A. B., Oxford Univ. Report (1975).

[5] Foreman E., Vieböck F. P., Wothe H., Can J. Phys. 46 (1967) 754.
[6] Alton G. D., IEEE Trans. Nucl. Sci. 23 (1976) 1113.

[7] Brand K., Nucl. Instrum. Methods 141 (1977) 519.

[8] Betz H. D., Rev. Mod. Phys. 44 (1972) 465.

[9] Wittkower A. B. and Betz H. D., At. Data 5 (1973) 113.

[10] Betz G., Dombrozemsky R., Vieböck F. P., Ned. Tijdscr. Vacuumtech. 8 (1970) 203.

[11] Doucas G., McK. Hyder H. R. and Knox A. B., Nucl. Instrum. Methods 124 (1975) 11.

[12] Ihmels G., JAeschKe E. and RePNow R., Nucl. Instrum. Methods 138 (1976) 407. 